\title{
Vascular Parkinsonism: A Clinical Review
}

\author{
Hani T.S. Benamer ${ }^{\mathrm{a}}$ Donald G. Grosset ${ }^{\mathrm{b}}$ \\ a Department of Neurology, Queen Elizabeth Neuroscience Centre, Queen Elizabeth University Hospital, \\ Birmingham, and ${ }^{\mathrm{b}}$ Department of Neurology, Institute of Neurological Sciences, Southern General Hospital, \\ Glasgow, UK
}

\section{Key Words}

Parkinsonism • Vascular parkinsonism • Parkinson's disease

\begin{abstract}
Over the last 75 years there has been continuous debate about the existence of vascular parkinsonism (VP). The condition has been named and renamed several times, with terms such as arteriosclerotic parkinsonism, arteriosclerotic pseudo-parkinsonism and lower-body parkinsonism. Despite the progress in our understanding of other parkinsonian syndromes, such as progressive supranuclear palsy and multiple-system atrophy, and significant developments in neuroimaging techniques, the concept of VP is still unclear and the clinical diagnosis is often difficult. There are no widely agreed diagnostic criteria. This article reviews the current literature relating to VP in particular to identify the different clinical presentations that have been described.
\end{abstract}

Copyright $\odot 2008$ S. Karger AG, Basel

\section{Introduction}

A parkinsonian syndrome may be caused by cerebrovascular disease, a concept introduced when Critchley [1] described 5 types of clinical presentation of what he termed arteriosclerotic parkinsonism in 1929. Rigidity, fixed faces and short-stepping gait were the main clinical signs. Pseudo-bulbar, pyramidal or cerebellar signs and the presence of dementia and incontinence were considered as additional features. After several clinical studies in the 1960s and 1970s had shown no relation between arteriosclerosis and Parkinson's disease (PD) [2-4], Critchley in 1981 renamed the condition arteriosclerotic pseudo-parkinsonism [5]. Several alternative terms have been used including vascular parkinsonism (VP) and lower-body parkinsonism (LBP), but there are no generally accepted clinical criteria to diagnose this condition.

With the development of computed tomography (CT) and magnetic resonance imaging (MRI) the concept of VP was revived [6-8]. This was supported by post-mortem studies showing vascular lesions in the striatum and lacunar infarcts in patients with clinical features very similar to PD, including an apparent response to levodopa, but with no evidence of Lewy bodies $[9,10]$. It has been estimated that parkinsonism due to cerebrovascular disease accounts for $3-12 \%$ of all cases of parkinsonism $[11,12]$. However, the true incidence and prevalence rates of VP are not known, as there are no specific diagnostic criteria.

\section{Clinical Features}

Several clinical features have been described relating brain vascular lesions to parkinsonism. Two patients presented with acute-onset parkinsonism due to vascular lesions in the basal ganglia, and there was recovery without anti-parkinsonian drugs $[13,14]$. A patient with acuteonset parkinsonism following an isolated vascular lesion on the right side of the substantia nigra and without dopaminergic therapy response is reported [15]. On the oth-

\section{KARGER}

Fax +4161306 1234

E-Mail karger@karger.ch

www.karger.com
(C) 2008 S. Karger AG, Base

0014-3022/09/0611-0011\$26.00/0

Accessible online at:

www.karger.com/ene
Hani T.S. Benamer

Neurology Department, Queen Elizabeth Neuroscience Centre

Queen Elizabeth University Hospital

Edgbaston, Birmingham B15 2TH (UK)

Tel. +44 1216978 221, Fax +44 1216978 402, E-Mail benamer@doctors.org.uk 
er hand, an insidious onset of parkinsonism resembling the pattern seen in idiopathic PD has been attributed to brain vascular infarcts $[7-10,16,17]$. Hughes et al. [10] reported, in a clinico-pathological study of 100 cases with a clinical diagnosis of $\mathrm{PD}, 3$ patients with lacunar infarcts and no Lewy bodies. Murrow et al. [9] described a 74year-old man with a 20 -year history of $\mathrm{PD}$, who presented with resting tremor. A positive dopaminergic response was supported by extreme worsening of bradykinesia and rigidity when L-dopa was discontinued relating to a surgical procedure. Additionally, he developed foot dystonia and motor fluctuations. At post-mortem, there was lacunar infarction in the basal ganglia without any evidence of coexistent Lewy bodies. A further patient with a history of resting and postural tremor, rigidity and cerebrovascular disease had improvement on L-dopa; autopsy showed cerebrovascular disease and no Lewy bodies [17]. In other reports, patients with parkinsonism had evidence of cerebrovascular disease on neuroimaging, but without post-mortem to confirm or refute pathological features of $\mathrm{PD}[7,8,16]$. Accordingly these latter cases may simply be describing patients with coexistent cerebrovascular disease and PD. In 17 patients with pathologically confirmed VP, a good or excellent L-dopa response was recorded in 12 (70\%) [29]. While these reports collectively suggest that some patients with clinically suspected VP respond to dopaminergic therapy [18], the case numbers are small, and the therapy responses are observational and often retrospective.

LBP is another clinical pattern suggesting a cerebrovascular cause for (or contribution to) parkinsonian features. FitzGerald and Jankovic [19] compared 10 patients with marked gait difficulty to 100 subjects with PD. Gait disturbance was the initial symptom in 7\% of PD cases. The only difference in vascular risk factors was an excess of hypertension in LBP. Only 22\% of LBP responded to levodopa, while $96 \%$ of PD did so. The scores for speech, hypomimia, neck rigidity, upper limb rest tremor, rigidity and hand dexterity were significantly lower in LBP, emphasising the relative sparing, though not absence, of upper body and trunk involvement. The duration of symptoms was considerably shorter in LBP than PD. All LBP patients had structural imaging (MRI and/or CT) performed, and multiple deep sub-cortical lesions were seen in all but one (90\%). On the other hand, only 4 of 8 MRI scans (50\%) and 1 of 34 CT scans (3\%) for patients with PD showed sub-cortical white matter lesions. Therefore, LBP may represent a group of patients, usually hypertensive, who have gait difficulty, symmetrical rigidity absent tremor, and minimal or no response to levodopa therapy. However, the specified clinical features were the basis of the diagnostic differentiation from PD and are mostly non-specific, also occurring for example in alternative forms of degenerative parkinsonism.

In a clinico-pathologic study, Yamanouchi and Nagura [20] compared the symptoms and signs of 24 patients with VP (defined as parkinsonism with evidence of cerebrovascular lesions and no depigmentation or Lewy bodies in the substantia nigra) with 30 age-matched pathologically confirmed PD patients. Also, they compared the brain pathological changes in VP patients with 22 agematched Binswanger's disease cases without parkinsonism. Resting tremor was present in 1 patient (4\%) and action tremor in 3 cases (12.5\%) with VP, while 22 patients (73\%) with PD had tremor. Nine subjects (37.5\%) with VP had hemiparesis and 15 (62.5\%) had pyramidal signs, while no hemiparesis or pyramidal signs were found in PD. Half of the patients with VP had pseudo-bulbar palsy, and $27 \%$ of the PD subjects had dysphasia or dysarthria. Dementia was present in $17 \mathrm{VP}(71 \%)$ and $13 \mathrm{PD}$ (43\%) cases. Fifteen VP patients $(62.5 \%)$ received antiparkinsonian medications; none showed good response, $3(12.5 \%)$ a transient response and the remaining 12 (12.5\%) no reaction, while the majority of PD patients responded positively. Asymmetry of limb rigidity was reported in 7 patients with VP (29\%) and 22 PD cases ( $73 \%)$. Interestingly, little difference was found in gait abnormality between VP (all patients had gait problems) and PD (23,77\% of patients). Pathologically, 11 PD subjects (37\%) had evidence of cerebrovascular disease. The white matter lesions in VP were less severe than Binswanger's disease, but the extent of vascular lesions in both groups was equal.

Winikates and Jankovic [21] reported a difference in the clinical features of VP compared to PD. They defined $\mathrm{VP}$ as patients with at least 2 of the 4 cardinal features of parkinsonism (bradykinesia, rigidity, tremor and postural instability) and 2 or more points on a newly designed vascular rating scale (2 points for pathologically or angiographically proven diffuse vascular disease, 1 for onset of parkinsonism within 1 month of clinical stroke, 1 point for history of 2 or more strokes, 1 point for history of 2 or more risk factors of stroke and 1 point for neuroimaging evidence of vascular disease in 2 or more vascular territories). They found that VP patients were older, more likely to present with gait difficulty rather than tremor and less likely to respond to levodopa. Also, VP patients tend to have more predominant lower-body involvement, postural instability, falls, dementia, corticospinal findings, incontinence and pseudo-bulbar palsy. 
Rampello et al. [22] examined 32 elderly patients with late-onset PD and 45 with VP. All subjects underwent brain MRI and were scored using the unified Parkinson's disease rating scale parts 2 and 3. They found that patients with PD had a younger age at onset and a longer duration of the disease compared to those with VP. Nearly all PD patients showed a good response to levodopa therapy, while only $29 \%$ of cases with VP were responsive to levodopa treatment. Vascular risk factors as well as postural tremor, gait disorders and pyramidal signs with lower-body predominance were more frequent in patients with VP. The majority of PD patients (93\%) had normal MRI, whereas all subjects with VP had cerebral vascular lesions. The Parkinson's disease rating scale scores at baseline were higher in VP than in PD patients.

Zijlmans et al. [23] reported 17 patients with suspected VP defined as 'parkinsonism and no pathological evidence of either idiopathic PD or any other histopathological condition known to be associated with a parkinsonian syndrome'. They found no difference in vascular risk factors between patients and controls, except that hypertension, and heart disease associated with stroke, were more common in the control group (which relates to their selection of hypertensive cases in the control patients). Clinically, most subjects presented with bilateral bradykinesia, rigidity and shuffling gait, while 4 presented with acute hemiparesis and then progressed to parkinsonism. These 4 patients had lacunae in the basal ganglia or thalamus.

\section{Diagnostic Criteria}

There are no agreed clinical diagnostic criteria for VP. Zijlmans et al. [23] proposed possible criteria for the clinical diagnosis of VP based on their study including:

(a) parkinsonism, defined as bradykinesia, and at least one of the following: rest tremor, rigidity or postural instability;

(b) cerebrovascular disease, defined as evidence of relevant cerebrovascular disease by brain imaging or the presence of focal signs or symptoms that are consistent with stroke;

(c) a relationship between (a) and (b): an acute or delayed progressive onset of parkinsonism (within 1 year) after stroke with evidence of infarcts in or near areas that increase the basal ganglion motor output or decrease the thalamocortical drive directly, or an insidious onset of parkinsonism with extensive sub-cortical white matter lesions, bilateral symptoms at the onset and the presence of early shuffling gait or early cognitive dysfunction.

Although neither these criteria nor prior clinically based definitions [21] have been generally applied either in research or clinical practice, it would increase comparability if future reports used them as a frame of reference.

\section{The Proposed Mechanisms of VP}

Various mechanisms have been discussed as explanation for VP. Ischaemic basal ganglion or white matter lesions disrupting the sensorimotor integration have been suggested $[8,9,14,16,24-26]$. The gait disorder in Binswanger's disease was attributed to diffuse vascular lesions disrupting basal ganglia/motor cortex connections [27] and Winikates and Jankovic [21] proposed it as a mechanism for VP.

\section{Imaging of Striatal Dopamine Transporters in VP}

Several studies looked at dopamine transporters in VP using $\left[{ }^{123} \mathrm{I}\right] \beta$-CIT single-photon emission computed tomography (SPECT) and $\left.{ }^{123} \mathrm{I}\right]$ FP-CIT SPECT. Gerschlager et al. [28] reported preserved or mild reduction in the striatal $\left[{ }^{123} \mathrm{I}\right] \beta$-CIT and putamen/caudate ratio in 13 patients with VP when compared to 20 PD cases. On the other hand, Zijlmans et al. [29] found that the mean striatal $\left.{ }^{[23} \mathrm{I}\right] \mathrm{FP}-\mathrm{CIT}$ uptake was significantly lower in $13 \mathrm{VP}$ patients than in healthy controls. When compared with the PD group, only the mean asymmetry index was significantly lower in VP patients. They suggested that in the majority of VP patients, the pre-synaptic dopaminergic function is reduced and they proposed using the asymmetry index as a criterion for the clinical diagnosis of VP.

Lorberboym et al. [30] studied 20 patients who developed VP in the course of cerebrovascular disease with $\left[{ }^{123} \mathrm{I}\right] \mathrm{FP}-\mathrm{CIT}$ SPECT and 20 healthy controls. Nine patients (45\%) had normal striatal [ $\left.{ }^{123} \mathrm{I}\right] \mathrm{FP}-\mathrm{CIT}$ binding similar to that of controls. In contrast, 11 patients (55\%) had significantly diminished striatal binding when compared with controls.

It is therefore difficult to reach any firm conclusion from available studies about the role of dopamine transporter imaging in VP. The lack of uniform clinical diagnostic criteria clearly contributes to difficulties of interpretation of the results, some of which are conflicting. Further research is needed. 


\section{The Association between Vascular Disease and PD}

The association between ischaemic stroke and vascular risk factors on the one hand and PD on the other has been addressed in several studies. The incidence of ischaemic stroke among PD patients was lower than that of controls in one study [31], but an association was found in another [32]. Cigarette smoking is recognised as protective for PD $[33,34]$ and a low incidence of both smoking and myocardial infarction is seen in PD patients [31, 32]. A retrospective case-control study of 178 patients with newly diagnosed PD, and 533 age- and sex-matched controls showed that diabetes, history of smoking, high blood pressure, high blood cholesterol and triglycerides were significantly less frequent in PD than controls [35]. Another study looked at the frequency of cerebrovascular lesions in 617 patients with autopsy-proven idiopathic $\mathrm{PD}$ and 535 age-matched controls. It found that $44.0 \%$ of PD patients had vascular lesions, more than was seen in controls (32.8\%), while acute, often fatal ischaemic or hemorrhagic strokes were less frequent in parkinsonian patients (1.8 vs. $2.6 \%)$. The study concluded that there is neither a protective effect of PD against stroke nor a greater susceptibility to death from stroke in the populations examined [36].

Thus PD may coexist with cerebrovascular disease, which is unsurprising as both disease processes increase with age. Postmortem studies provide definite evidence of the coexistence of PD and cerebrovascular disease, and they suggest that patients with parkinsonism may have cerebrovascular disease without the pathological hallmark features of PD $[9,10]$.

\section{Conclusions}

Parkinsonism occurring in patients with cerebrovascular, mainly lacunar, disease has been clearly documented in cases without autopsy evidence of Lewy bodies. Observational evidence suggests that some such patients have a dopaminergic therapy response. Clinical patterns taking 3 forms are described: (a) gait difficulty, symmetrical rigidity and absent tremor, mainly in patients with history of hypertension, often referred to as LBP, which may be the most common form; (b) a more insidious onset of parkinsonism with reasonable similarity to idiopathic $\mathrm{PD}$, and some indication of a dopaminergic therapy response, and (c) acute-onset parkinsonism, due to vascular lesions in the basal ganglia, which is relatively rare. However, despite significant advances in both imaging and pathological reports, the studies remain small and are difficult to compare due to a lack of consensus criteria. Crucially for patient management, the relationship between cerebrovascular disease and the therapy response in subjects with parkinsonism is not well defined.

\section{References}

1 Critchley M: Arteriosclerotic parkinsonism. Brain 1929;52:23-83.

-2 Eadie MJ, Suterland JM: Arteriosclerosis in parkinsonism. J Neurol Neurosurg Psychiatry 1964;27:237-240.

3 Parkes JD, Marsden CD, Rees JE, et al: Parkinson's disease, cerebral arteriosclerosis, and senile dementia. Q J Med 1974;169:4961.

4 Marttila RJ, Rinne UK: Arteriosclerosis, heredity, and some other previous infections in etiology of Parkinson's disease: a case control study. Clin Neurol Neurosurg 1976;79: 46-56.

5 Critchley M: Arteriosclerotic pseudo-parkinsonism; in Rose C, Capildeo R (eds): Research Progress in Parkinson's Disease. London, Pitman Medical, 1981, pp 40-42.

-6 Chang CM, Yu YL, Leung SY, Fong KY: Vascular pseudoparkinsonism. Acta Neurol Scand 1992;86:588-592.
7 Inzelberg R, Bornstein NM, Reider I, Korc-
zyn AD: Basal ganglia lacunes and parkin-
sonism. Neuroepidemiology 1994;13:108-
112 .
8 Reider-Groswasser I, Bornstein NM, Korc-
zyn AD: Parkinsonism in patients with lacu-
nar infarcts of the basal ganglia. Eur Neurol
1995;35:46-49.
Murrow RW, Schweiger GD, Kepes JJ, Koller
WC: Parkinsonism due to a basal ganglia laWC: Parkinsonism due to a basal ganglia la-
cunar state: clinicopathologic correlation. Neurology 1990;40:897-900.

10 Hughes AJ, Daniel SE, Kilford L, Lees AJ: Accuracy of clinical diagnosis of idiopathic Parkinson's disease: a clinico-pathological study of 100 cases. J Neurol Neurosurg Psychiatry 1992;55:181-184.

-11 Thanvi B, Lo N, Robinson T: Vascular parkinsonism - an important cause of parkinsonism in older people. Age Ageing 2005;34: 114-119.
12 Sibon I, Tison F: Vascular parkinsonism. Curr Opin Neurol 2004;17:49-54.

13 Friedman A, Kang UJ, Tatemichi TK, Burke $\mathrm{R}$ : A case of parkinsonism following striatal lacunar infarction (letter). J Neurol Neurosurg Psychiatry 1986;49:1087-1088.

14 Mayo J, Arias M, Leno C, Berciano J: Vascular parkinsonism and periarteritis nodosa (letter). Neurology 1986;36:874.

15 Akyol A, Akyildiz UO, Tataroglu C: Vascular parkinsonism: a case of lacunar infarction localized to mesencephalic substantia nigra. Parkinsonism Relat Disord 2006;12: 459-461.

16 Tolosa ES, Santamaria J: Parkinsonism and basal ganglia infarcts. Neurology 1984;34: 1516-1518.

17 Mark MH, Sage JI, Walters AS, Duvoisin RC, Miller DC: Binswanger's disease presenting as levodopa-responsive parkinsonism: clinicopathologic study of three cases. Mov Disord 1995;10:450-454. 
- 18 Zijmans JC, Katzenschlager R, Daniel SE, Lees AJ: The L-dopa response in vascular parkinsonism. Neurol Neurosurg Psychiatry 2004;75:545-547.

-19 FitzGerald PM, Jankovic J: Lower body parkinsonism: evidence for vascular etiology. Mov Disord 1989;4:249-260.

-20 Yamanouchi H, Nagura H: Neurological signs and frontal white matter lesions in vascular parkinsonism: a clinicopathologic study. Stroke 1997;28:965-969.

21 Winikates J, Jankovic J: Clinical correlates of vascular parkinsonism. Arch Neurol 1999; 56:98-102.

-22 Rampello L, Alvano A, Battaglia G, Raffaele $\mathrm{R}$, Vecchio I, Malaguarnera M: Different clinical and evolutional patterns in late idiopathic and vascular parkinsonism. J Neurol 2005;252:1045-1049.

-23 Zijlmans JC, Daniel SE, Hughes AJ, Revesz T, Lees AJ: Clinicopathological investigation of vascular parkinsonism, including clinical criteria for diagnosis. Mov Disord 2004;19: 630-640.

-24 Zijlmans JC, Thijssen HO, Vogels OJ, Kremer HP, Poels PJ, Schoonderwaldt HC, Merx JL, Van Hof MA, Thien T, Horstink MW: MRI in patients with suspected vascular parkinsonism. Arch Neurol 1995;52:1017-1022.
25 Baloh RW, Vinters HV: White matter lesions and disequilibrium in older people. I. Casecontrol comparison. Arch Neurol 1995;52: 970-974.

26 Baloh RW, Yue Q, Socotch TM, Jacobson KM: White matter lesions and disequilibrium in older people. II. Clinicopathological correlation. Arch Neurol 1995;52:975-981.

27 Thompson PD, Marsden CD: Gait disorder of subcortical arteriosclerotic encephalopathy: Binswanger's disease. Mov Disord 1987; 2:1-8.

28 Gerschlager W, Bencsits G, Pirker W, Bloem BR, Asenbaum S, Prayer D, Zijlmans JC, Hoffmann M, Brucke T: $\left[{ }^{123} \mathrm{I}\right]$ beta-CIT SPECT distinguishes vascular parkinsonism from Parkinson's disease. Mov Disord 2002; 17:518-523.

29 Zijlmans J, Evans A, Fontes F, Katzenschlager R, Gacinovic S, Lees AJ, Costa D: $\left[{ }^{123} \mathrm{I}\right] \mathrm{FP}$ CIT SPECT study in vascular parkinsonism and Parkinson's disease. Mov Disord 2007; 22:1278-1285.
30 Lorberboym M, Djaldetti R, Melamed E, Sadeh M, Lampl Y: 123I-FP-CIT SPECT imaging of dopamine transporters in patients with cerebrovascular disease and clinical diagnosis of vascular parkinsonism. J Nucl Med 2004;45:1688-1693.

>31 Struck LK, Rodnitzky L, Dobson JK: Stroke and its modification in Parkinson's disease. Stroke 1990;21:1395-1399.

32 Levine RL, Jones JC, Bee N: Stroke and Parkinson's disease. Stroke 1992;23:839-842.

-33 Baumann RJ, Jameson HD, McKean HE, Haack DG, Weisberg LM: Cigarette smoking and Parkinson disease. I. Comparison of cases with matched neighbors. Neurology 1980;30:839-843.

34 Morens DM, Grandinetti A, Davis JW, Ross GW, White LR, Reed D: Evidence against the operation of selective mortality in explaining the association between cigarette smoking and reduced occurrence of idiopathic Parkinson disease. Am J Epidemiol 1996; 144:400-444

35 Scigliano G, Musicco M, Soliveri P, Piccolo I, Ronchetti G, Girotti F: Reduced risk factors for vascular disorders in Parkinson disease patients: a case-control study. Stroke 2006; 37:1184-1188.

-36 Jellinger KA: Prevalence of cerebrovascular lesions in Parkinson's disease: a postmortem study. Acta Neuropathol 2003;105:415-419. 